\title{
On the application of $\mathrm{NiO}$ nanoparticles to mitigate in situ asphaltene deposition in carbonate porous matrix
}

\author{
Seyed Iman Hashemi • Babak Fazelabdolabadi • \\ Siyamak Moradi • Ali Morad Rashidi • \\ Abbas Shahrabadi · Hadi Bagherzadeh
}

Received: 22 December 2014/ Accepted: 1 February 2015/Published online: 17 February 2015

(C) The Author(s) 2015. This article is published with open access at Springerlink.com

\begin{abstract}
Prevention of asphaltene formation in reservoir rocks can result in resolving a severe long-lasting issue in petroleum production. The present research addresses the issue in the context of exploring the potential effect of nickel oxide $(\mathrm{NiO})$ nanoparticles in destabilizing asphaltene deposition in porous media, in the presence of carbon dioxide. To ensure proper distribution within the system and to retain future field-scale applicability, the $\mathrm{NiO}$ nanoparticles were exposed to the in situ oil via injection gas stream, in which they had been uniformly dispersed using polydimethylsiloxane (PDMS). The experimental results, established under miscible $\mathrm{CO}_{2}$ state, indicate a considerable improvement in permeability/porosity reduction of core, as well as less asphaltene accumulation in porous media and increased oil recovery factor after applying $\mathrm{NiO}$ nanoparticles.
\end{abstract}

Keywords Nanoparticle $\cdot$ Asphaltene . Carbonate matrix $\cdot$ Nickel oxide

\section{S. I. Hashemi · S. Moradi}

Faculty of Petroleum Engineering, Petroleum University of Technology (PUT), Abadan, Iran

B. Fazelabdolabadi $(\square) \cdot$ A. Shahrabadi $\cdot$ H. Bagherzadeh Institute of Enhanced Oil Recovery, Center for Exploration and Production Studies and Research, Research Institute of Petroleum Industry (RIPI), West Blvd. Azadi Sports Complex, P.O. Box 14665-1998, Tehran, Iran

e-mail: fazelb@ripi.ir

\section{A. M. Rashidi}

Nanotechnology Research Center, Research Institute of Petroleum Industry (RIPI), West Blvd. Azadi Sports Complex, P.O. Box 14665-1998, Tehran, Iran

\section{Introduction}

Nanotechnology has growingly found considerable applications in many branches of science as well as in the petroleum industry. The main feature of nanoparticles making their application appealing is their size and the capability of characteristics manipulation. Within the petroleum industry domain, the main attraction resides with the nanoparticles' remarkable mobility, due to their size, which allows them to effectively flow through reservoir pores $(<1 \mu \mathrm{m})$. Moreover, the characteristics of nanoparticles can be modified to favorably alter the rheological/surface tension/wettability properties of injecting (nano) fluid (Kapusta et al. 2012), particularly useful to enhanced oil recovery (EOR) applications.

A number of studies have been conducted to analyze the effect of metal oxide nanoparticles on asphaltene inhibition. These included experiments with oil samples containing dissolved gas in the solution (live oil sample) and oil samples without dissolved gas (dead oil sample). Mohammadi et al. (2011), for instance, conducted experiments with dead oil samples under static conditions to study the effects of $\mathrm{TiO}_{2}, \mathrm{SiO}_{2}$ and $\mathrm{ZrO}_{2}$ nanoparticles, and concluded that $\mathrm{TiO}_{2}$ nanoparticles can enhance the stability of asphaltene nanoaggregates through formation of hydrogen bonds at acidic conditions $(\mathrm{pH}<4)$ and having an inverse effect at basic conditions. Nasser et al. (Nassar et al. 2012a, b; Nassar et al. 2011) experimentally confirmed the ability of $\mathrm{NiO}, \mathrm{CO}_{3} \mathrm{O}_{4}$ and $\mathrm{Fe}_{3} \mathrm{O}_{4}$ nanoparticles to improve the thermal decomposition of asphaltenes. The catalytic activity of the selected nanoparticles toward asphaltene decomposition was then determined as $\mathrm{NiO}>\mathrm{CO}_{3} \mathrm{O}_{4}>$ $\mathrm{Fe}_{3} \mathrm{O}_{4}$. Moreover, it was revealed through experiments with $\mathrm{Fe}_{3} \mathrm{O}_{4}$ nanoparticles (Nassar et al. 2012a, b; Nassar et al. 2011) that such adsorption/oxidation rate increases 
with decrease in the molecular weight of the asphaltenes. Some studies focusing on $\mathrm{NiO}$ nanoparticles (Abu Tarboush and Husein 2012a, b) explored the remarkable affinity characteristics of $\mathrm{NiO}$ nanoparticles toward adsorption of asphaltenes, which indeed served as our main motivation for its choice in the present work. More recently, Franco et al. (2013) studied the effects of different types of nanoparticles for causing delay or inhibition in asphaltene deposition in porous media under flow conditions. The experiments unveiled the good property of the considered nanoparticles in having relatively short adsorption equilibrium time for asphaltene ( $\sim 2 \mathrm{~min})$, which implies promising potential of delaying agglomeration and inhibition of asphaltene precipitation in porous media.

On the other hand, asphaltene precipitation is a major issue affecting EOR success. Since miscible $\mathrm{CO}_{2}$ injection is considered a major EOR technique, substantial research was devoted to study the formation damage induced by asphaltene precipitation/deposition during miscible $\mathrm{CO}_{2}$ injection. Sim et al. (2005), for example, used core flooding tests to investigate the reduction in permeability at pressure and temperature conditions of reservoir under miscible $\mathrm{CO}_{2}$ injection. Their results indicated that the degree of formation damage, induced by the same $\mathrm{CO}_{2}$ /oil mixture, was related to the initial permeabilities, with higher damage occurring in higherpermeable cores. Experimental results by Hayashi and Okabe (2010) on sandstone and carbonate cores under dynamic gas injection showed asphaltene being equally distributed in the core (in the case of associated gas injection), while being mainly deposited near the core inlet (in case of $\mathrm{CO}_{2}$ injection). Studies performed on asphaltene precipitation under dynamic $\mathrm{CO}_{2}$ injection also report permeability reduction in sandstone cores in immiscible $\mathrm{CO}_{2}$ state (Wang et al. 2013). Recently, Wang and $\mathrm{Gu}$ (2011) performed dynamic $\mathrm{CO}_{2}$ flooding tests in sandstone cores in both miscible/immiscible states. It was concluded that the onset pressure of asphaltene precipitation is much lower than the minimum miscible pressure (MMP). Moreover, the oil recovery factor was determined to be higher and the oil effective permeability reduction to be larger at a higher injection pressure (in immiscible $\mathrm{CO}_{2}$ case) while reaching nearly constant maximum values in the miscible $\mathrm{CO}_{2}$ case ( $P \geq$ MMP). For a comprehensive review of the subject the reader is referred to the article by Wang and $\mathrm{Gu}$ (2011) and the references therein.

The present study entails analysis of the inhibition effect of $\mathrm{NiO}$ nanoparticles on asphaltene under dynamic miscible $\mathrm{CO}_{2}$ core flooding. The work bears the distinction that it addresses the issue of $\mathrm{NiO}$ effectiveness within the context of $\mathrm{CO}_{2}$ presence in porous media.

\section{Experimental setup and procedure}

Figure 1 shows a schematic view of the high-temperaturehigh-pressure (HTHP) apparatus used in the present work. The instrument is designed such that the analysis of asphaltene precipitation under dynamic oil-flow conditions in porous media can be attained. The apparatus is mainly composed of the following sections:

A high-pressure positive displacement (DBR) pump, allowing fluid displacement under constant pressure or flow rate; transfer vessel, intended for storage or transfer of fluid; differential pressure transducer, which measures the pressure difference between the two ends of the core with a precision of $0.1 \mathrm{psi}$; back-pressure regulator, used for regulating the pressure of the fluid exiting the core; gas flow meter and scaled sampler, used for measurement of gas and fluid produced, respectively; core holder, used for holding the core which can stand pressures up to 10,000 psi and temperatures up to $200{ }^{\circ} \mathrm{C}$; manual pump to apply confining pressures around the core; heating system and temperature controller for heating and applying different temperatures to the system.

The core holder, situated vertically, is composed of a stainless steel cylindrical body and a rubber sleeve, into which the core is placed. The empty space between the cylindrical body and the sleeve is filled by a fluid, through which the confining pressure is applied on the outer surface of the sleeve. This pressure on the outer surface area of the sleeve, the confining pressure, is always adjusted to be above the pressure of the fluid being injected into the core, such that the injecting fluid does not flow through the empty space between the core and the sleeve. A spacer which is made of stainless steel and having circular groove is placed at the end of the sleeve to make sure that the injected fluid is distributed at the whole surface area of the core sample and also the inside of the core holder is filled.

The positive displacement pump, which is capable of applying pressures up to $15,000 \mathrm{psi}$, causes fluid to flow into the core, at a constant flow rate, by applying pressure to the bottom of the transfer vessel. The DBR pump can ensure fluid injection at a flow rate of $0.01 \mathrm{cc} / \mathrm{h}$. To achieve the temperature conditions of the reservoir, the core holder is placed inside the heating system, in which the temperature is automatically controlled. The pressure of the output fluid is controlled by the back-pressure regulator. Fluids, after passing through the DBR pump, enter the scaled sampler and gas is directed into the gas flow meter.

\section{Materials}

The live oil sample used, with properties enlisted in Table 1, was obtained from an Iranian oilfield. The 
Fig. 1 Schematic of the experimental setup

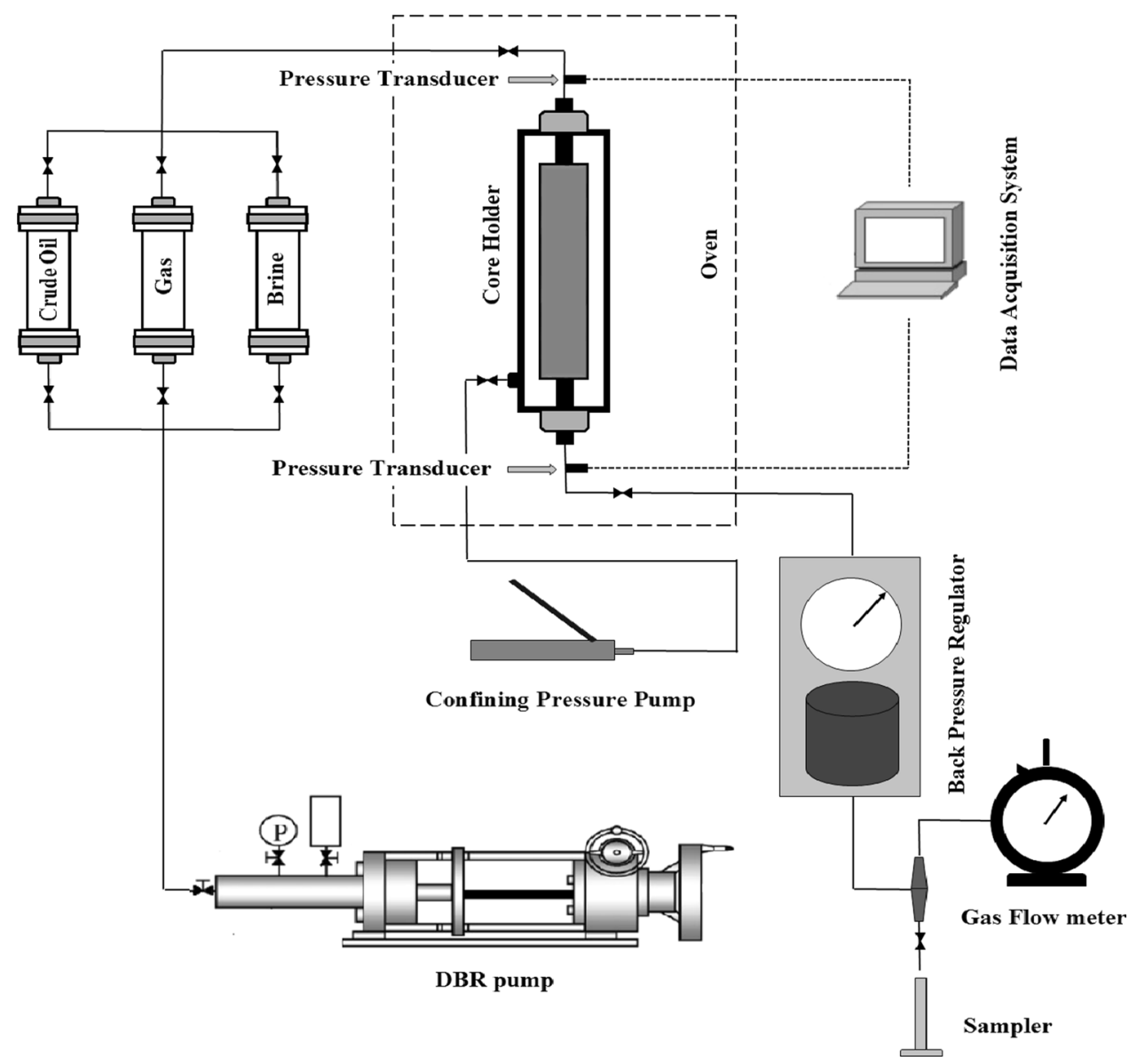

Table 1 Properties of the live oil sample used, and the experimental temperature

\begin{tabular}{ll}
\hline Reservoir temperature & $120{ }^{\circ} \mathrm{C}$ \\
API & 27.48 \\
Saturation pressure & $5,369 \mathrm{psi}$ \\
Oil formation volume factor at saturation pressure & $2.7953 \mathrm{Rbbl} / \mathrm{STB}$ \\
Density of oil at saturation pressure & $0.5982 \mathrm{~g} / \mathrm{cc}$ \\
Viscosity of oil at saturation pressure & $0.1949 \mathrm{cp}$. \\
\hline
\end{tabular}

asphaltene content of the oil sample used was determined through SARA test to be nearly $4.33 \%$ (Table 2). The core samples used were all of carbonate type, with petro-physical characteristics enlisted in Table 3 .

Nanoparticle synthesis and analysis

The nanoparticle chosen in the present work was nickel oxide nanoparticle, which was produced through the spray pyrolysis method. In essence, the spray pyrolysis involves a process in which nanoparticles are precipitated over a hot surface through spraying of a solution. The considered solution is turned into fine droplets inside a gas and is subsequently sprayed onto a reactor, over which chemical
Table 2 SARA test results of the oil sample contents (by weight percent)

\begin{tabular}{llll}
\hline Saturates & Aromatics & Resins & Asphaltene \\
\hline 48.77 & 30.93 & 15.95 & 4.33 \\
\hline
\end{tabular}

reactions occur to form chemical species. The reacting elements are chosen such that the undesired chemical species produced are volatile under reaction conditions. The process is highly suitable for production of nanostructured oxides (Mooney and Radding 1982; Patil 1999). Figure 2 shows a typical spraying system used in this research. It mainly consists of a spraying nozzle, reactor, precursor solution, two electric furnaces, temperature controller, bag filter, and air compressor or gas propellant. The reactor was made of stainless that had $5 \mathrm{~cm}$ diameter and $240 \mathrm{~cm}$ length, and the diameter of the nozzle used to spray the solution was $1 \mathrm{~mm}$.

The material used for synthesis of nickel oxide nanoparticles was nickel acetate $\left(\mathrm{C}_{4} \mathrm{H}_{6} \mathrm{NiO}_{4}\right)$ from Merck. Initially, an adequate amount of nickel acetate was dissolved in water, and then citric acid solvent was added to 
Table 3 Petro physical properties of core samples

\begin{tabular}{lllllll}
\hline Test number & Core type & Length $(\mathrm{cm})$ & Diameter $(\mathrm{cm})$ & Grain density $(\mathrm{g} / \mathrm{cc})$ & Porosity $(\%)$ & Air permeability $(\mathrm{md})$ \\
\hline 1 & Carbonate & 5.019 & 3.734 & 2.687 & 8.093 & 2.982 \\
2 & Carbonate & 5.001 & 3.718 & 2.687 & 16.953 & 7.285 \\
3 & Carbonate & 5.001 & 3.718 & 2.687 & 15.941 & 6.943 \\
\hline
\end{tabular}

Fig. 2 Schematic of the spray pyrolysis setup used in this research

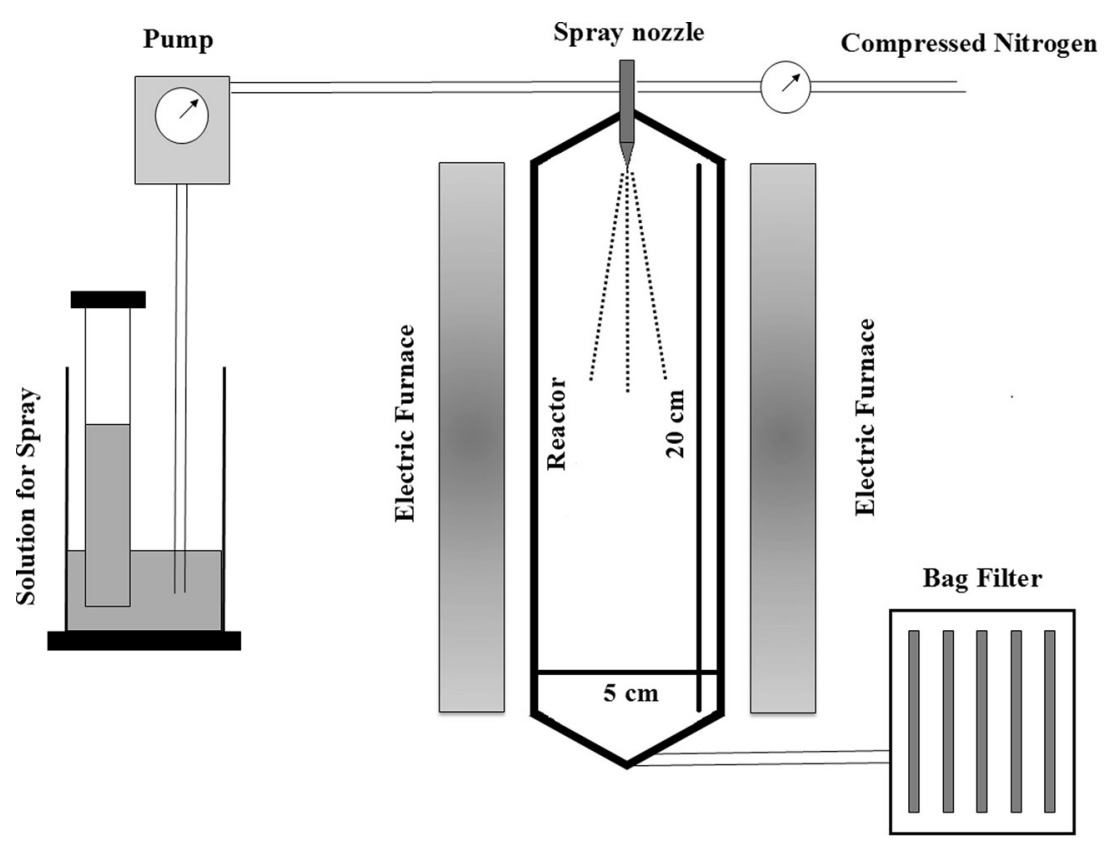

the mixture in stoichiometric ratio, forming a homogeneous gel. The droplets of the produced solution were dispersed into the carrying gas and transported to the reaction environment. The mixture of the carrying gas and solution gas enters through the pressure nozzle into the spray pyrolysis reactor, operating at a temperature between 500 and $600{ }^{\circ} \mathrm{C}$. Following the reaction, the available solvent was evaporated and left the produced fine solid particles behind. The solid phase was then separated from the vapor phase by a bag filter. Figure 3 shows the X-ray diffraction (XRD) analysis of the particles produced. As observed, the XRD results depict peaks at angles of $43^{\circ}, 52^{\circ}$, and $75^{\circ}$.

The mean crystalline size of the produced particles was calculated by application of Scherrer 's equation (Mohammadiani et al. 2012):

$D=K \lambda / \beta \cos \theta$,

where $D$ is the mean crystalline size of powder, $\lambda$ is the radiation wavelength of $\mathrm{Cu}, \mathrm{k}_{\alpha}$ (here taken to be $1.54056 \AA$ ), $\beta$ is the full width at half-maximum (FWHM) intensity of the second peak, $\theta$ is the Bragg's diffraction angle and $K$ is a constant, usually equal to 0.9. The mean crystalline size of the produced $\mathrm{NiO}$ powder was $D=60 \mathrm{~nm}$.

\section{Experimental procedure}

To analyze the process of asphaltene precipitation in oil flow inside porous media and the effect of nanoparticle presence in the process, three experiments were devised. The main parameters considered in these three experiments were the change in permeability/porosity, the change in the asphaltene content, and the change in the oil recovery factor.

The first experiment (EXP-1) involved injection of live oil into the core, to analyze the effects of injection pressure and flow rate, which also entails the mechanism of organic material precipitation during the natural depletion process. At first, to study the effect of injection pressure, live oil was injected into the core at a temperature of $120^{\circ} \mathrm{C}$ and constant flow rate of $9(\mathrm{cc} / \mathrm{h})$ and at pressure intervals of $5,500,6,000$, and 6,600 psi. Then, at the pressure of 5,400 psi which is close to the oil's bubble point pressure, core injection was attempted under three altered flow-rate conditions of 6,9 , and $18(\mathrm{cc} / \mathrm{h})$. The asphaltene content of the oil was determined based upon the IP 143 (ASTM D6560) standard method (Energy Institute 2005).

In the second experiment (EXP-2), the asphaltene precipitation inside the core was studied by injecting $\mathrm{CO}_{2}$ into the core. The injection of carbon dioxide was attempted 


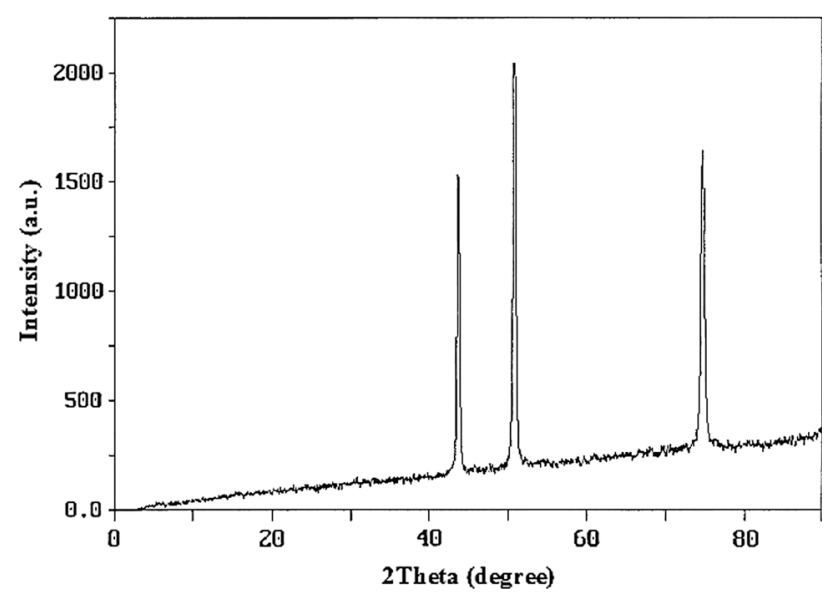

Fig. 3 XRD pattern of $\mathrm{NiO}$ nanoparticles

under miscible conditions, pertaining to pressures above the minimum miscible pressure.

The procedure was initiated by saturating the core fully with reservoir formation water and then raising the system temperature to the reservoir temperature considered $\left(120^{\circ} \mathrm{C}\right)$. The DBR pressure was set to 6,000 psi. The absolute permeability was measured by injecting reservoir water under three different flow rates. The wettability and saturation of connate water (Swi) were also measured by injecting cyclohexane under three different flow rates. The core was then saturated with live oil sample by injection at a constant flow rate. This was followed by injection of $\mathrm{CO}_{2}$, to displace the oil inside the core and sampling of output oil for asphaltene content determination. The change in permeability of the core, after gas injection, was measured by re-injection of cyclohexane under essentially similar conditions.

In the third experiment (EXP-3), to study the effect of nanoparticle presence on asphaltene precipitation, nickel oxide nanoparticles were dispersed into $\mathrm{CO}_{2}$. To facilitate comparison, the third set of experiment was carried out under the same procedures of EXP-2, with the exception that the injecting $\mathrm{CO}_{2}$ in this case was the carbon dioxide stream saturated with nanoparticles as opposed to the pure $\mathrm{CO}_{2}$ case. Polydimethylsiloxane (PDMS) was used for dispersing nickel oxide nanoparticles into $\mathrm{CO}_{2}$, as suggested in the literature (Shah and Rusheet 2009).

The devised procedure for nanoparticle dispersion first involved mixing $\mathrm{NiO}$ nanoparticles with PDMS at a ratio of 1:3. The nanofluid was then exposed to ultrasonic waves for a duration of $30 \mathrm{~min}$, to avoid particle clogging and ensure uniform distribution inside the PDMS. A certain value of nanofluid was placed inside an accumulator and $\mathrm{CO}_{2}$ was then injected into the accumulator. The pressure inside the accumulator was raised above the mixing pressure of the PDMS dispersant and $\mathrm{CO}_{2}(2,500 \mathrm{psi})$. The accumulator was shaken for a duration of $24 \mathrm{~h}$ to enhance the dispersion quality, after which the accumulator pressure was raised to the injection pressure of interest.

Dynamic light scattering (DLS) tests were conducted to ascertain the particle size distribution of asphaltene in the injecting as well as produced oil samples in EXP-3, using Zetasizer ${ }^{\circledR}$ ZS (Malvern Instruments, Worcestershire, UK).

\section{Results}

First experiment

As discussed earlier, the aim of EXP-1 was to investigate the effect of pressure reduction and flow-rate change on the asphaltene precipitation phenomenon during a natural depletion process. Such pressure reduction is conceivable in producing oilfields and is considered as a contributing factor to the asphaltene issue. To approach our goal, we initially calculated the absolute permeability of the core, after saturation with water, using Darcy's equation under three different flow rates:

$k=Q L \mu / A \Delta P$,

where $k$ is the permeability in Darcy, $Q$ is the flow rate in the core in $\mathrm{cm}^{3} / \mathrm{s}, L$ is the effective core length (i.e., the length over which the pressure drop is measured) in $\mathrm{cm}, \mu$ is the fluid viscosity in centipoises, $A$ is the cross-sectional area of the core in $\mathrm{cm}^{2}$, and $\Delta P$ is the pressure drop along the core length in atm. The absolute permeability of the core sample was calculated as $0.28678 \mathrm{md}$. The absolute permeability can be determined from single flow-rate data; nevertheless, we attempted to determine it over three different flow rates and its average value has been taken into account.

Oil injection was attempted at a constant flow rate of 9 $(\mathrm{cc} / \mathrm{h})$ and the temperature and pressure conditions of $120^{\circ} \mathrm{C}$ and 6,600 psi, respectively. Oil injection was continued until the pressure difference between the two ends of the core was stabilized. Then, the process was repeated by changing the injection pressure to 6,000 and 5,500 psi. The oil permeability was continuously measured by recording the pressure difference alongside the core. Owing to low permeability of the considered core sample, precipitation of a small amount of asphaltene should bring about a considerable reduction in permeability. However, the permeability results, as shown in Figs. 4, 5 and 6, do not exhibit a notable reduction. At a pressure of $6,600 \mathrm{psi}$, permeability variations increased; yet they did not follow a particularly stable pattern. Such small permeability variations are because of the existence of connate water. In other words, such small variations last until the water leaves the core and its saturation in the core reaches Swi (30\% in our 
case). Permeability variations in other injection pressures have been nominal and have followed a stable pattern.

Determination of asphaltene content in the output oil samples shows the asphaltene amount to have nominal change and to remain nearly equivalent to its initial value in the process. This indicates that the asphaltene had not

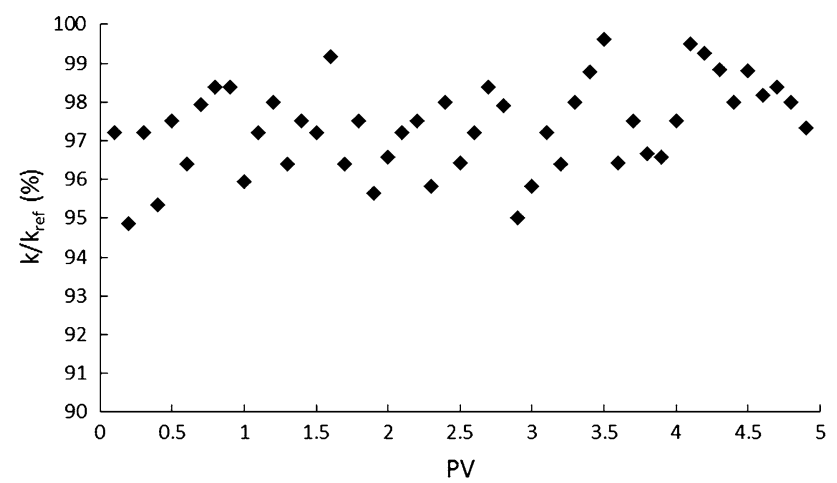

Fig. 4 Percentage of the ratio of permeability $(k)$ to reference permeability $\left(k_{\text {ref }}\right)$ against oil-injected pore volumes $(\mathrm{PV})$ at an injection pressure of $6,600 \mathrm{psi}$ and a flow rate of $9(\mathrm{cc} / \mathrm{h})$

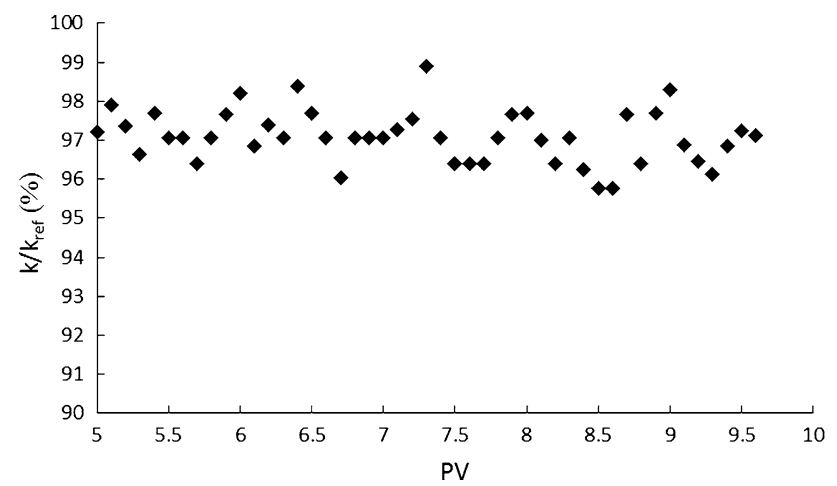

Fig. 5 Percentage of the ratio of permeability $(k)$ to reference permeability $\left(k_{\text {ref }}\right)$ against oil-injected pore volumes at an injection pressure of $6,000 \mathrm{psi}$ and a flow rate of $9(\mathrm{cc} / \mathrm{h})$

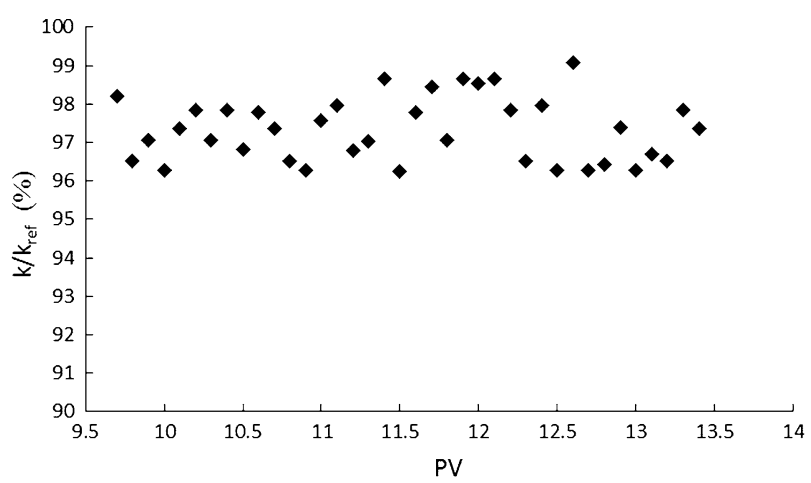

Fig. 6 Percentage of the ratio of permeability $(k)$ to reference permeability $\left(k_{\text {ref }}\right)$ against oil-injected pore volumes at an injection pressure of $5,500 \mathrm{psi}$ and a flow rate of $9(\mathrm{cc} / \mathrm{h})$ undergone any precipitation in the core, which is partially in contrast to some literature results (Mohammadi et al. 2011). It also indicates the ineffectiveness of the considered parameters on asphaltene precipitation, in this case. Figure 7 shows the asphaltene content of output oil against the injection pore volume (PV).

Having completed the analysis of pressure reduction effect, the flow-rate effect was afterward considered by conducting experiments under three different injection flow-rate conditions: namely, 6, 9, and 18 (cc/h). Subsequently, the injection process was carried out at a pressure of 5,500 psi, which is essentially close to the bubble point pressure of the oil sample. Figures 8, 9, 10, and 11 depict the corresponding permeability change/asphaltene content results. It can be deducted from the figures that the flowrate change, likewise pressure reduction, did not have notable change on asphaltene precipitation.

\section{Second experiment}

Since EXP-2 involved injection of $\mathrm{CO}_{2}$ to study the effect of change in oil composition, it was essential to first

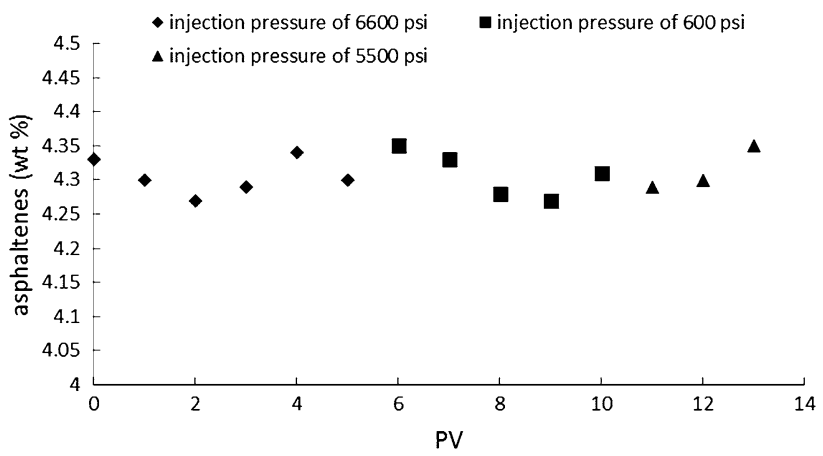

Fig. 7 Asphaltene content of oil produced (wt \%) against oil-injected pore volumes during oil injection at different injection pressures and a constant flow rate of $9(\mathrm{cc} / \mathrm{h})$

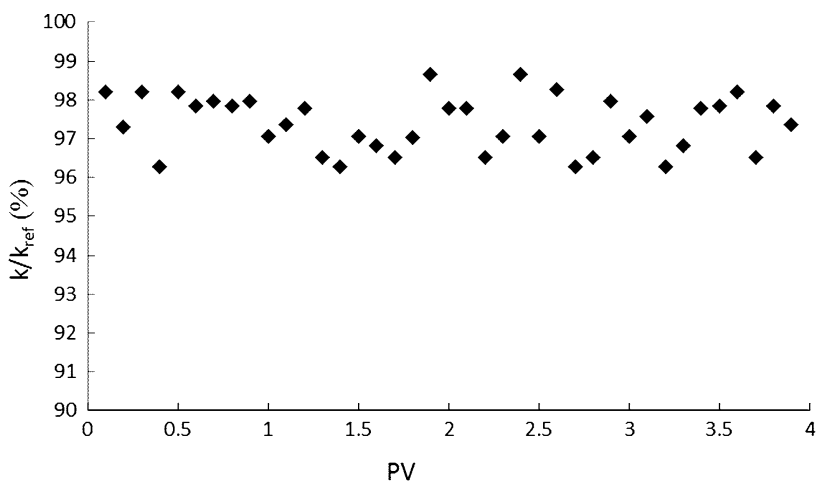

Fig. 8 Percentage of the ratio of permeability $(k)$ to reference permeability $\left(k_{\text {ref }}\right)$ against oil-injected pore volumes at an injection pressure of $5,500 \mathrm{psi}$ and a flow rate of $9(\mathrm{cc} / \mathrm{h})$ 


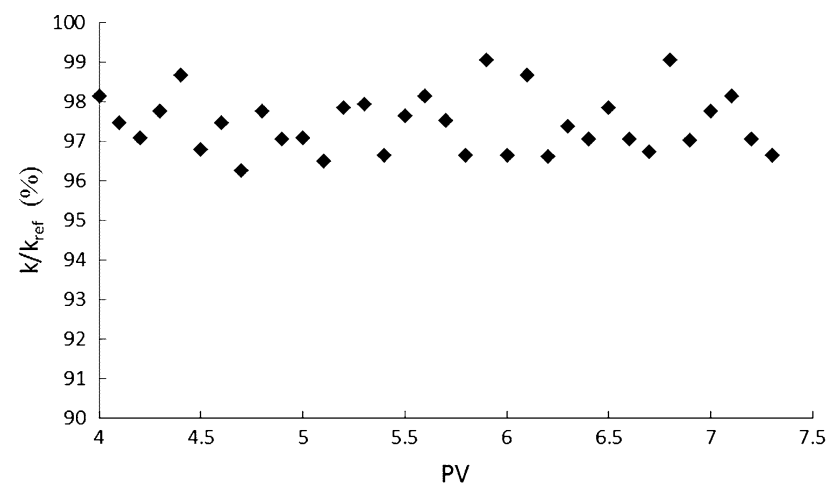

Fig. 9 Percentage of the ratio of permeability $(k)$ to reference permeability $\left(k_{\text {ref }}\right)$ against oil-injected pore volumes at an injection pressure of $5,500 \mathrm{psi}$ and a flow rate of $6(\mathrm{cc} / \mathrm{h})$

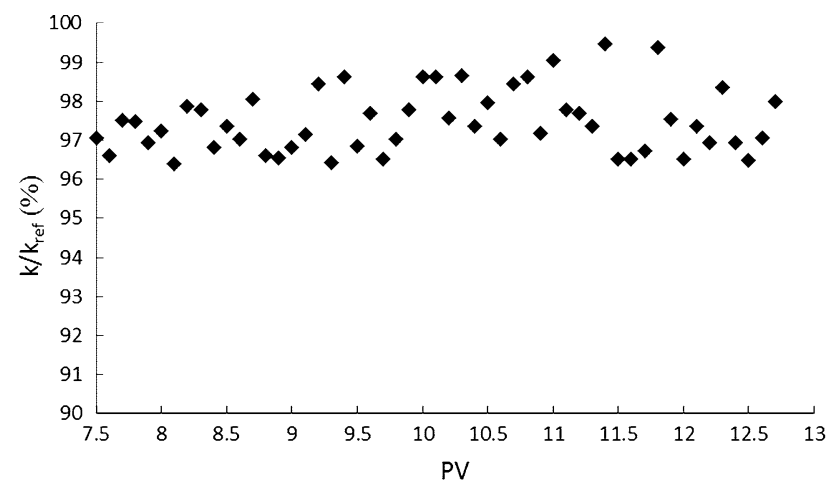

Fig. 10 Percentage of the ratio of permeability $(k)$ to reference permeability $\left(k_{\text {ref }}\right)$ against oil-injected pore volumes at an injection pressure of 5,500 psi and a flow rate of $18(\mathrm{cc} / \mathrm{h})$

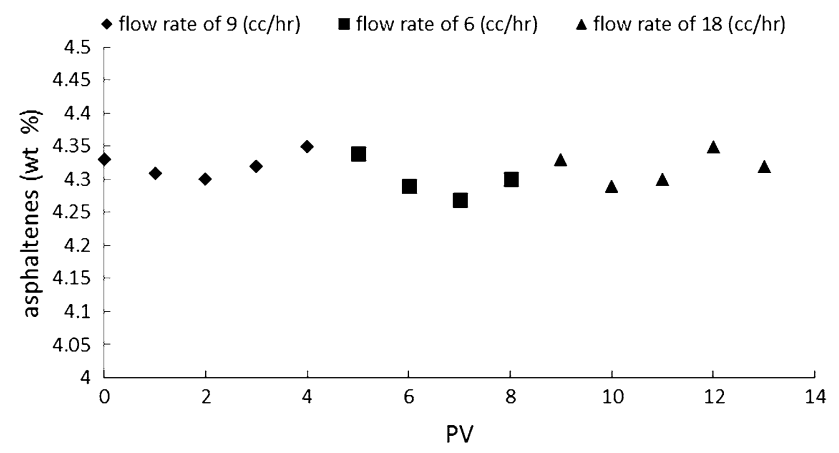

Fig. 11 Asphaltene content of oil produced (wt \%) against oilinjected pore volumes during oil injection at a constant injection pressure of 5,500 psi and different flow rates

determine the minimum miscible pressure to delineate miscible conditions. The MMP pressure was calculated, based on the oil PVT data, injecting gas composition and experimental temperature, and found to be close to 5,700 psi. However, EXP-2 was conducted at an over-MMP pressure $(6,000 \mathrm{psi})$ to secure $\mathrm{CO}_{2}$ miscibility at $120{ }^{\circ} \mathrm{C}$.

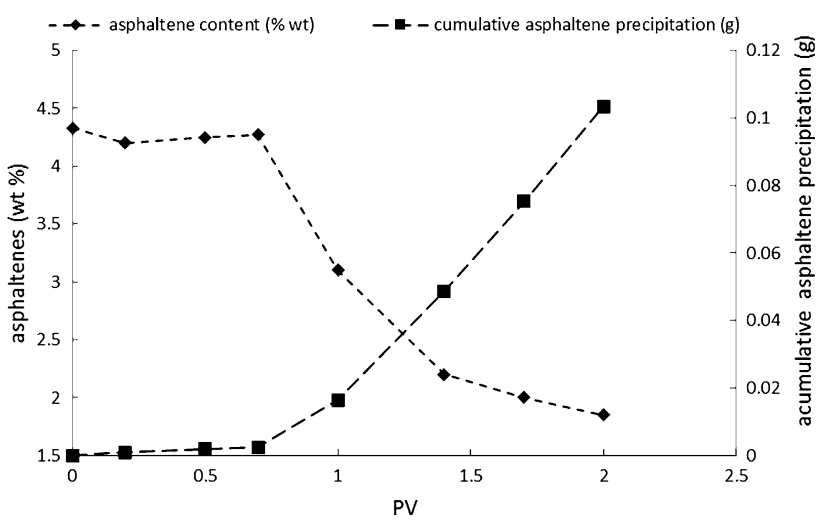

Fig. 12 Asphaltene content of produced oil (wt \%) and cumulative mass of asphaltene precipitated in the core against gas-injected pore volumes during miscible $\mathrm{CO}_{2}$ injection in EXP-2

To avoid core plugging during EXP-2, core samples with higher permeability/porosity than the corresponding EXP-1 cores were selected, but the core type essentially remained unchanged (i.e., of carbonate type). Evaluation of permeability during the gas injection process was not attainable, due to continuous change in the composition of injecting fluid during miscible gas injection process, which brought about continuous change in fluid viscosity. Therefore, to determine the core permeability, before and after gas injection, it was necessary to employ a fluid with essentially neutral functionality toward asphaltene particles, and in which the asphaltenes are insoluble. Cyclohexane was chosen for this purpose, by which core permeability was determined both before and after gas injection. The results confirmed that asphaltene particles reduced the permeability by as much as $20 \%$.

The amount of output asphaltene remained almost unchanged until the gas break-through (roughly corresponding to injecting of $0.7 \mathrm{PV}$ of gas into the core) and was decreased afterward, indicating asphaltene precipitation in the core. The output asphaltene was measured using IP 143 standard. Once the information of the asphaltene value in the input/output streams is known, the amount of asphaltene precipitates in the core can be readily established using material balance. Figure 12 shows the amount of output asphaltene (by weight percentage) as well as the amount of asphaltene precipitation in the core against the pore volume amount of injecting gas.

The asphaltene precipitates inside the core occupy part of the available (non-matrix) space and will cause reduction in porosity. Figure 13 shows the percentage ratio of porosity over the initial porosity of the core against the pore volume amount of injecting gas. It is obvious that asphaltene precipitates have less severe effect on porosity than permeability.

In EXP-2, the oil recovery factor (RF) was nearly $70 \%$, with a larger portion being produced before the gas break- 


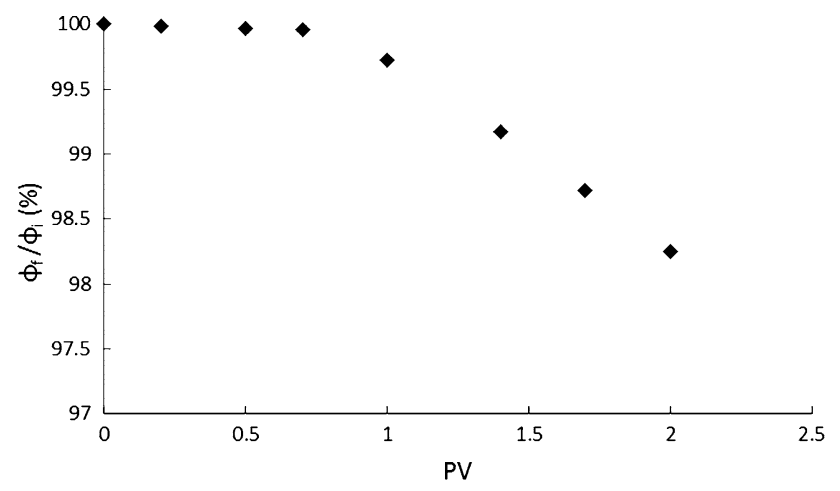

Fig. 13 Percentage of the ratio of porosity $\left(\Phi_{\mathrm{f}}\right)$ to initial porosity $\left(\Phi_{i}\right)$ against gas-injected pore volumes during miscible $\mathrm{CO}_{2}$ injection by asphaltene deposition in EXP-2

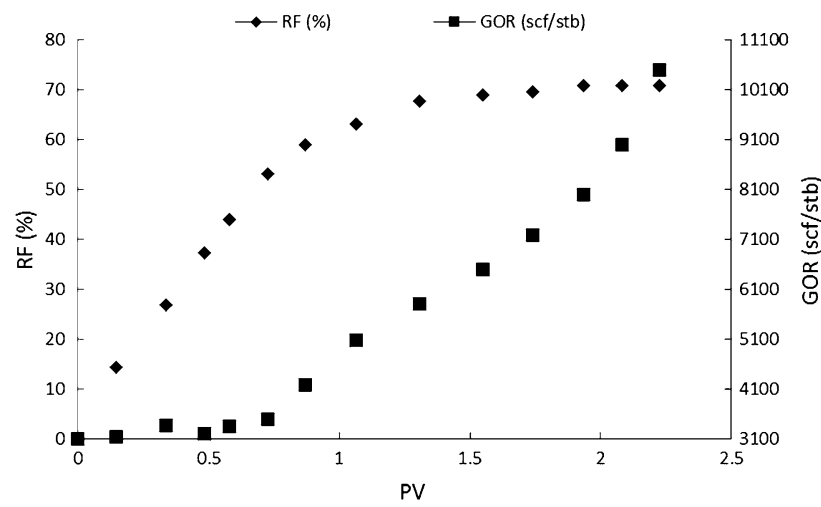

Fig. 14 Oil recovery factor (RF) and gas oil ratio (GOR) against gasinjected pore volumes during miscible $\mathrm{CO}_{2}$ injection in EXP-2

through stage. Figure 14 illustrates the oil recovery factor and the gas/oil ratio (GOR) obtained during the injection process.

\section{Third experiment}

In EXP-3, the application of nanoparticles as potential asphaltene inhibitor was studied under dynamic conditions. Our choice of nanoparticle was hinted by its previous usage in the literature under the static mode (Nassar et al. 2012). For practical reasons, $\mathrm{NiO}$ nanoparticles were dispersed in $\mathrm{CO}_{2}$ prior to injection into the oil. This is due to the fact that in practice, the injection of nanoparticles into the in situ oil is not accomplishable in the field scale, and the mere pragmatic approach for its exposure to the in situ oil in the reservoir is through mixing with the injecting gas stream during the enhanced oil recovery process. Table 4 lists the description of the nanofluid used in EXP-3.

The identically same core sample was used both in EXP2 and EXP-3, after washing with toluene. Although toluene
Table 4 The description of the nanofluid used in EXP-3

\begin{tabular}{lll}
\hline Component & Type & Weight percentage (wt \%) \\
\hline Nanoparticle & $\mathrm{NiO}^{\mathrm{a}}$ & 1 \\
Dispersant & $\mathrm{PDMS}$ & 2 \\
Base fluid & $\mathrm{CO} 2$ & 97 \\
\hline
\end{tabular}

${ }^{a}$ Mean crystalline size $60 \mathrm{~nm}$

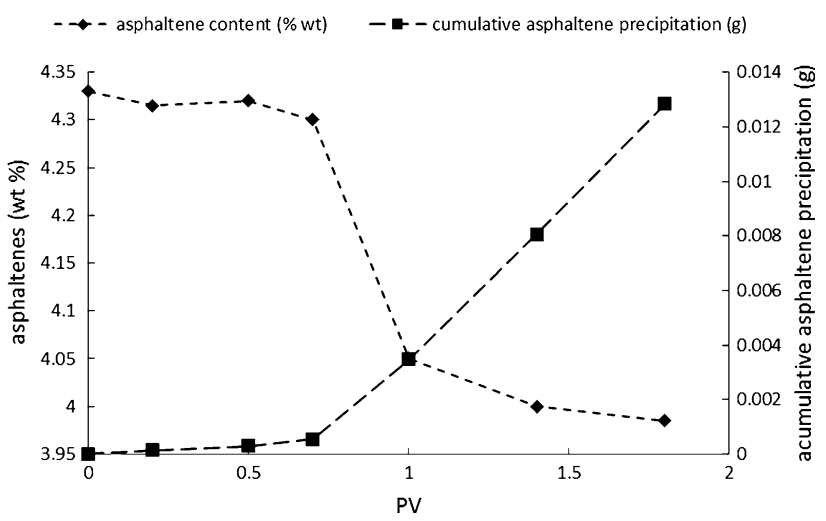

Fig. 15 Asphaltene content of produced oil (wt \%) and cumulative mass of asphaltene precipitated in the core against gas-injected pore volumes during nanosaturated $\mathrm{CO}_{2}$ injection in EXP-3

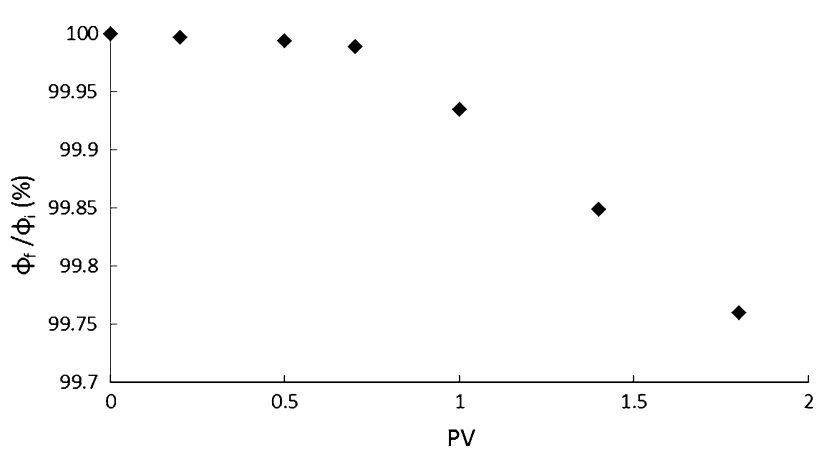

Fig. 16 Percentage of the ratio of porosity $\left(\Phi_{\mathrm{f}}\right)$ to the initial porosity $\left(\Phi_{i}\right)$ against gas-injected pore volumes during nanosaturated $\mathrm{CO}_{2}$ injection by asphaltene deposition

is considered as a suitable solvent for asphaltene, the porosity/permeability of the core little decreased after toluene application in EXP-3, which can be described in two ways. First, some of the asphaltene particles had precipitated in small pores (possibly blocking the pores during EXP-2), the removal of which should require usage of a large amount of toluene solvent. Second, a permeability reduction of core might have occurred during EXP-2 alongside an alteration in rock wettability. Precipitation of asphaltene, in this case, may alter the wettability of the core to that of oil wet; therefore, even if toluene had succeeded in removing all the asphaltene particles from porous 
media (precipitated during EXP-2), it failed in reverting the wettability conditions to the original state.

The change in permeability of core, before and after gas injection, was less in EXP-3 $(\sim 2 \%)$ compared to EXP-2 ( $\sim 20 \%$ ), which indicates less asphaltene precipitate formation in this case. Figure 15 shows the weight percentage of output asphaltene and its precipitated amount in the core against the PV of injection gas. Similar to EXP-2, the asphaltene content of output oil remained constant until gas break-through, and afterward it decreased. Such reduction value, however, has been nominal in the EXP-3 case, as opposed to EXP-2. The percentage ratio of porosity over

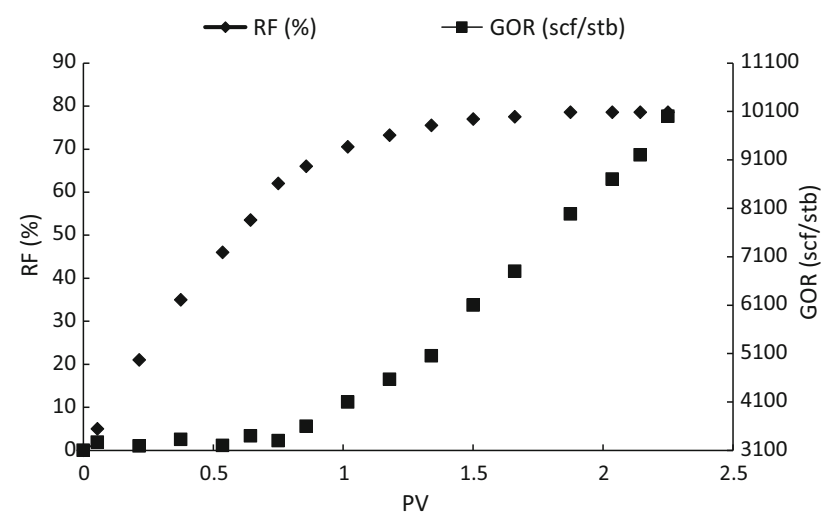

Fig. 17 Oil recovery factor (RF) and gas oil ratio (GOR) against gasinjected pore volumes during nanosaturated $\mathrm{CO}_{2}$ injection

Table 5 Summary of results for EXP-2 and EXP-3

\begin{tabular}{lcc}
\hline & EXP-2 & EXP-3 \\
\hline Swi variation (\%) & 0 & 0 \\
Accumulated asphalatene in core (g) & 0.1033 & 0.0128 \\
Permeability reduction (\%) & 20 & 2 \\
Porosity reduction (\%) & 1.2 & 0.24 \\
Oil Recovery Factor $(\%)$ & 71 & 78.57 \\
\hline
\end{tabular}

initial core porosity is shown in Fig. 16. It is evident that the change in core porosity is somewhat negligible during the EXP-3 process. Compared to EXP-2, the oil recovery factor increased by $7 \%$. In fact, in EXP-2, the large amount of asphaltene precipitates can clog some of the available pore throats (entrapping oil in the core). Such a problem was further resolved in EXP-3, alongside reduction in asphaltene precipitation, and the gas stream was left with more accessible sites and was able to remove a larger portion of the in situ oil. The results for the oil recovery factor and GOR against injection gas PV is shown in Fig. 17. The summarized results for the EXP-2 and EXP-3 tests are tabulated in Table 5.

Figures 18 and 19 show particle size distribution of asphaltenes in injecting/produced oil samples in EXP-3, established via DLS. The size distribution results exhibit two peaks at 717 and $5,560 \mathrm{~nm}$, in case of injecting the oil sample, while having a single-peak distribution with peak (most intensity) occurring at 2,190 nm and average asphaltene particle sizes about $1,930 \mathrm{~nm}$, in case of produced oil. Such reduction in particle size can be interpreted in terms of $\mathrm{NiO}$ functionality in terms of decomposition of asphaltene aggregates.

The EXP-3 results confirm the effectiveness of $\mathrm{NiO}$ nanoparticles in inhibiting the formation of asphaltene precipitate particles in porous media. Owing to their small particle size, the nanoparticles can easily undergo motions in porous space. Moreover, their large surface area, as well as surface charge, would act as additional parameters of nanoparticle to inhibit asphaltene deposition formation. Alongside the change in oil composition during the gas injection process, the asphaltene particles are destabilized; nevertheless, such good parameters will cause the destabilized asphaltene particles to either precipitate on the nanoparticle surface or suspend indefinitely in oil, therefore reducing the risk of asphaltene deposition in rock and the concomitant formation damage.
Fig. 18 Particle size distribution of asphaltenes obtained by dynamic light scattering for the injecting oil sample in EXP-3
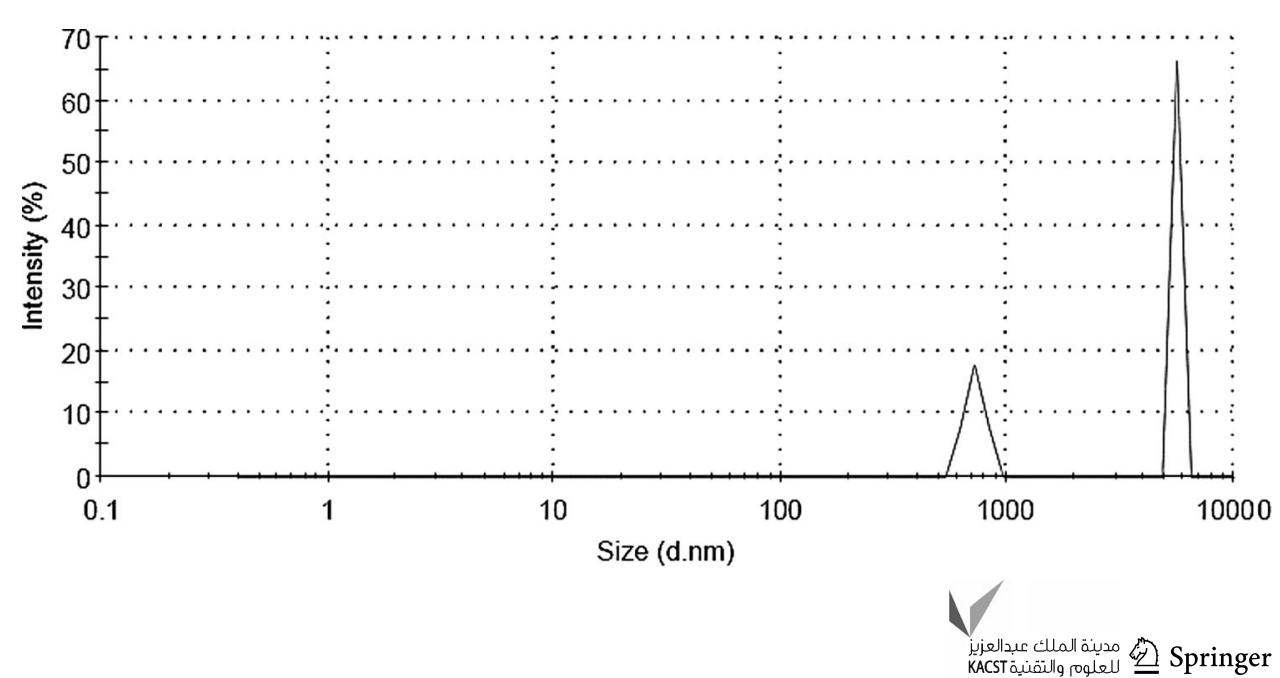
Fig. 19 Particle size distribution of asphaltenes obtained by dynamic light scattering for oil produced in EXP-3

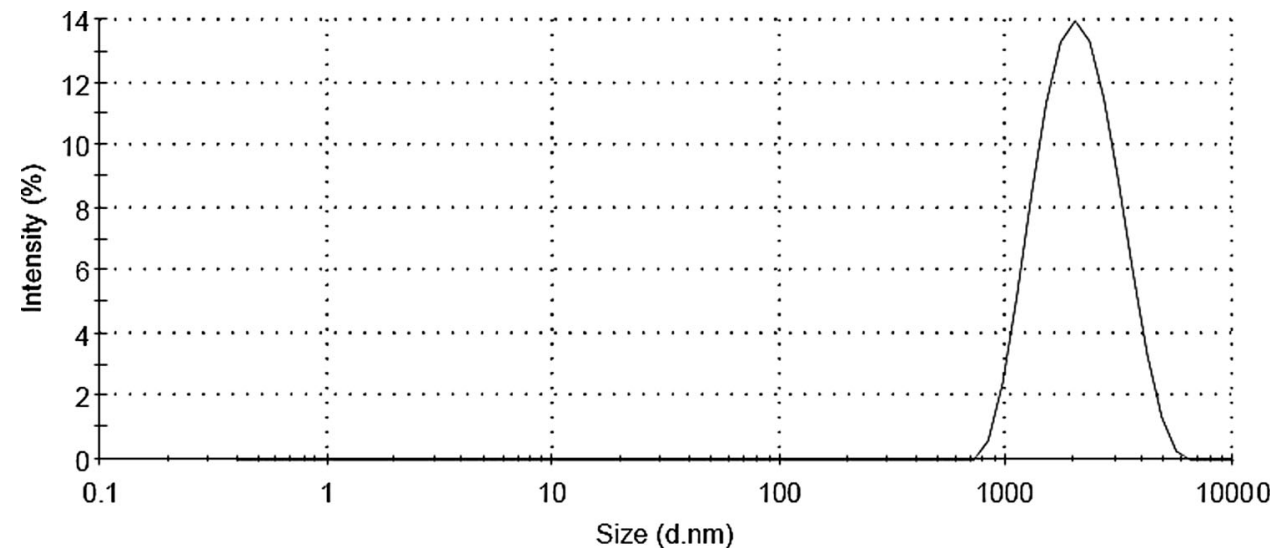

\section{Conclusions}

A series of dynamic core flooding tests were devised to assess the effectiveness of $\mathrm{NiO}$ nanoparticles to inhibit asphaltene precipitation/deposition in porous media. For our typical case of live oil sample and (reservoir) temperature/pressure conditions, the preliminary test EXP-1 showed the ineffectiveness of some parameters such as flow rate (over considered pressure reduction intervals) on causing severe asphaltene deposition in core samples in the natural depletion process. The ensuing EXP-2 case report showed an increased level of formation damage/asphaltene deposition, which can partly be accounted for by $\mathrm{CO}_{2}$ presence in the system and its induced adverse effects in contributing toward asphaltene flocculation. Comparison of EXP2 and EXP-3, conducted in an identical core sample, indicates the application of $\mathrm{NiO}$ nanoparticles to produce favorable results. Under miscible $\mathrm{CO}_{2}$ conditions, EXP-3 showed a considerable improvement in permeability reduction in the core sample $(\sim 2 \%)$ compared to EXP-2 $(\sim 20 \%)$. The porosity reduction also follows a similar improving trend in the EXP- 3 case $(\sim 0.24 \%)$ compared to its EXP-2 counterpart $(\sim 1.2 \%)$. The accumulated asphaltenes in core were reduced from a value of 0.1033 (g) in EXP-2 to 0.0128 (g) in EXP-3, over essentially identical experimental situations. Alongside reduction in accumulated asphaltene precipitates in the porous media, the oil recovery factor was obtained at a higher value in EXP-3 (78.57 \%) compared to EXP-2 (71\%), which can be conceived by availability of more accessible sites to injection gas for removal of in situ oil. A nominal reduction in core porosity/permeability after toluene application in EXP-3 can be described by possible blockage by accumulated asphaltene particles in EXP-2, the removal of which should require usage of a large amount of toluene solvent, as well as the inability of toluene in reverting the wettability conditions of rock surface from the induced oilwet condition to its original state. Given the favorable results established in EXP-3, and the excellent affinity/ oxidizing characteristics of $\mathrm{NiO}$ nanoparticles toward asphaltene, it holds great promise in being used as an effective asphaltene inhibitor/destabilizer in field-scale $\mathrm{CO}_{2}$ injection EOR processes.

Acknowledgments The authors would like to place on record their appreciation for the support rendered by the Research and Technology Directorate/National Iranian Oil Company to the research leading to the present article.

Open Access This article is distributed under the terms of the Creative Commons Attribution License which permits any use, distribution, and reproduction in any medium, provided the original author(s) and the source are credited.

\section{References}

Abu Tarboush BJ, Husein MM (2012a) Adsorption of asphaltenes from heavy oil onto in situ prepared $\mathrm{NiO}$ nanoparticles. J Colloid Interface Sci. doi:10.1016/j.jcis.2012.04.016

Abu Tarboush BJ, Husein MM (2012b) Oxidation of asphaltenes adsorbed onto $\mathrm{NiO}$ nanoparticles. Appl Catal A Gen. doi:10. 1016/j.apcata.2012.08.019

Energy Institute (2005) IP Standard test methods for analysis and testing of petroleum and related products. London

Franco CA, Nassar NN, Ruiz MA, Pereira-Almao P, Cortés FB (2013) Nanoparticles for inhibition of asphaltenes damage: adsorption study and displacement test on porous media. Energy Fuels. doi:10.1021/ef4000825

Hayashi Y, Okabe H (2010) Experimental investigation of asphaltene induced permeability reduction, SPE EOR Conference at oil and gas West Asia, Muscat, Oman. doi:10.2118/129271-MS

Kapusta S, Balzano L, Riele PT (2012) Nanotechnology applications in oil and gas exploration and production. Int Petro Technol Conf. doi: $10.2523 / 15152-M S$

Mohammadi M, Akbari M, Fakhroueian Z, Bahramian A, Azin R, Arya $\mathrm{S}$ (2011) Inhibition of asphaltene precipitation by $\mathrm{TiO} 2, \mathrm{SiO} 2$, and ZrO2 nanofluids. Energy Fuels. doi:10.1021/ef2001635

Mohammadiani D, Hosseini SA, Sadrenezhaad SK (2012) characterization of nickel oxide nanoparticles synthesized via rapid microwave assisted route. Int J Mod Phys Conf Series. doi:10. 1142/S2010194512002127

Mooney BJ, Radding SB (1982) Spray pyrolysis processing. Rev Mater Sci, Annu. doi:10.1146/annurev.ms.12.080182.000501 
Nassar NN, Hassan A, Pereira-Almo P (2011) Application of nanotechnology for heavy oil upgrading: catalytic steam gasification/cracking of asphaltenes. Energy Fuels. doi:10.1021/ ef 2001772

Nassar NN, Hassan A, Pereira-Almao P (2012a) Thermogravimetric studies on catalytic effect of metal oxide nanoparticles on asphaltene pyrolysis under inert conditions. J Therm Calorim. doi:10.1007/s10973-011-2045-0

Nassar NN, Hassan A, Carbognani L, Lopez-Linares F, PereiraAlmao P (2012b) Iron oxide nanoparticles for rapid adsorption and enhanced catalytic oxidation of thermally cracked asphaltenes. Fuel. doi:10.1016/j.fuel.2011.09.022

Patil PS (1999) Versatility of chemical spray pyrolysis technique. Chem Phys Mater. doi:10.1016/S0254-0584(99)00049-8
Shah R, Rusheet D (2009) Application of nanoparticle saturated injectant gases for EOR of heavy oils, SPE Annual Technical Conference and Exhibition. New Orleans

Sim SSK, Takabayashi K Okatsu K (2005) Asphaltene-induced formation damage: effect of asphaltene particle size and core permeability. SPE Annual Technical Conference and Exhibition, Dallas, Texas. doi: 10.2118/95515-MS

Wang X, Gu Y (2011) Oil Recovery and permeability reduction of a tight sandstone reservoir in immiscible and miscible $\mathrm{CO}_{2}$ flooding processes. Eng Chem Res, Ind. doi:10.1021/ie1016046

Wang T, Song Y, Zhao Y, Liu Y, Zhu N (2013) Measurement of immiscible $\mathrm{CO} 2$ flooding processes and permeability reduction due to asphaltene precipitation by X-ray CT imaging. Energy Procedia. doi:10.1016/j.egypro.2013.06.624 